\title{
Perbandingan Tekanan Darah Sebelum dan Sesudah Olahraga Angkat Berat
}

\author{
${ }^{1}$ Griffta R. Manansang \\ ${ }^{2}$ Jimmy F. Rumampuk \\ ${ }^{2}$ Maya E. W. Moningka
}

\author{
${ }^{1}$ Program Studi Pendidikan Dokter Fakultas Kedokteran Universitas Sam Ratulangi Manado \\ ${ }^{2}$ Bagian Fisika Fakultas Kedokteran Universitas Sam Ratulangi Manado \\ Email: rifca.71@hotmail.com
}

\begin{abstract}
Physical exercise involves musculoskeletal system as well as the other systems inter alia cardiovascular system, respiratory system, and excretory system. During exercise, the organs experience acute adaptation, one of which is the increased work of the heart which can be monitored through blood pressure. Blood pressure can vary depending on the situations including physical exercise. This study was aimed to obtain the difference in blood pressure of weight lifters before and after weight lifting. A non-random sampling technique was performed with a cross-sectional design. This study was conducted at Hardcore Gym Manado from November to December 2015. There were 38 subjects consisting of 27 males (71.1\%) and 11 females (28.9\%). The results showed that there were differences in systolic and diastolic blood pressures between before and after weight lifting, as follows: the means of systolic blood pressure before and after weight lifting were $113.947 \pm 7.8290$ vs 197.315 $\pm 9.4871 \mathrm{mmHg}$ and the means of diastolic blood pressure before and after weight lifting were $77.157 \pm 5.3551$ vs. $95.473 \pm 4.0983 \mathrm{mmHg}$. The Wilcoxon signed rank test showed a significant difference in blood pressure before and after weight lifting $(P=0.000)$. Conclusion: There are differences in blood pressure before and after weight lifting among weight lifters.
\end{abstract}

Keywords: blood pressure, weight lifting

\begin{abstract}
Abstrak: Olahraga tidak hanya melibatkan sistem muskuloskeletal semata, namun juga mengikutsertakan sistem lain seperti sistem kardiovaskular, sistem respirasi, sistem ekskresi. Organ-organ tubuh mengalami adaptasi akut, salah satunya meningkatkanya kerja jantung yang dapat dilihat melalui tekanan darah. Tekanan darah dapat berubah-ubah bergantung situasi seperti olahraga. Penelitian ini bertujuan untuk mengetahui perbandingan tekanan darah sebelum dan sesudah olahraga angkat berat. Penelitian ini dilakukan pada pelaku olahraga angkat berat di Hardcore Gym Manado yang dilaksanakan pada bulan November-Desember 2015. Penelitian ini menggunakan teknik non random sampling dengan desain potong lintang yang dilakukan pada 38 subyek. Subyek berjenis kelamin laki-laki sebanyak 27 orang $(71,1 \%)$ dan yang berjenis kelamin perempuan sebanyak 11 orang $(28,9 \%)$. Hasil penelitian menunjukkan terdapat perbedaan hasil pengukuran tekanan darah sistolik (TDS) dan tekanan darah diastolik (TDD) sebelum dan sesudah olahraga angkat berat yaitu TDS sebelum dan sesudah olahraga angkat berat sebesar $113,947 \pm 7,8290$ vs $197,315 \pm 9,4871 \mathrm{mmHg}$ dan TDD sebelum dan sesudah olahraga angkat berat sebesar $77,157 \pm 5,3551$ vs $95,473 \pm 4,0983 \mathrm{mmHg}$. Hasil uji Wilcoxon signed rank test menunjukkan perbedaan tekanan darah sebelum dan sesudah olahraga angkat berat yang bermakna dengan nilai $P=0,000$. Simpulan: Terdapat perbedaan tekanan darah yang bermakna sebelum dan sesudah olahraga angkat berat pada pelaku olahraga angkat berat.
\end{abstract}

Kata kunci: tekanan darah, olahraga angkat berat 
Tekanan darah merupakan tekanan yang dipompa oleh jantung terhadap dinding arteri. ${ }^{P}$ Sistem pembuluh darah sebagai tempat mengalirnya darah dari jantung, menyebar ke seluruh jaringan dan kembali ke jantung. Tekanan darah timbul ketika darah bersirkulasi di dalam pembuluh darah. ${ }^{2}$ Fungsi utama pembuluh darah arteri untuk mendistribusikan darah yang kaya oksigen dari jantung ke seluruh jaringan. Fungsi vena ialah mengalirkan darah yang membawa sisa metabolisme dan $\mathrm{CO}_{2}$ dari jaringan kembali ke jantung. Pada peredaran paru-paru, pembuluh darah arteri yang masuk paru-paru miskin $\mathrm{O}_{2}$ dan kaya $\mathrm{CO}_{2}$, sedangkan pembuluh darah vena yang keluar paru-paru kaya $\mathrm{O}_{2}{ }^{3}$ Peningkatan atau penurunan tekanan darah akan memengaruhi homeostatis dalam tubuh. ${ }^{4}$

Tekanan puncak terjadi saat ventrikel berkontraksi dan disebut tekanan sistolik. Tekanan diastolik adalah tekanan terendah yang terjadi saat ventrikel beristirahat dan mengisi ruangannya. ${ }^{5}$ Tekanan darah biasanya digambarkan sebagai rasio tekanan sistolik terhadap tekanan diastolik, dengan nilai dewasa berkisar dari 100/60 sampai 140/90. Rerata tekanan darah normal ialah 120/80. ${ }^{6}$ Klasifikasi tekanan darah pada orang dewasa dibagi menjadi kelompok normal, prehipertensi, hipertensi derajat satu, dan hipertensi derajat dua. ${ }^{7}$ Nilai tekanan darah anak-anak lebih rendah dari pada orang dewasa. Terdapat beberapa faktor yang memengaruhi tekanan darah. Faktor utama ialah jantung, tahanan perifer, volume darah, viskositas darah, dan distensi pembuluh darah, ${ }^{3}$ sedangkan faktor tambahan ialah usia, jenis kelamin, stres, ras, obesitas, dan juga aktivitas tubuh seperti berolahraga. ${ }^{8-12}$ Olahraga akan menyebabkan tekanan darah meningkat untuk waktu yang singkat dan akan kembali normal ketika berhenti berolahraga. ${ }^{13}$

Olahraga adalah suatu bentuk kegiatan fisik yang dapat meningkatkan kebugaran jasmani. Saat olahraga tidak hanya melibatkan sistem muskuloskeletal semata, namun juga mengikutsertakan sistem lain seperti sistem kardiovaskular, sistem respirasi, sistem ekskresi sistem saraf, dan lainnya.
Olahraga mempunyai arti penting dalam memelihara kesehatan dan menyembuhkan tubuh yang tidak sehat. ${ }^{14}$ Selain itu, olahraga dapat mencegah risiko terjadinya penyakit seperti penyakit pembuluh darah koroner, diabetes, kanker, dan lainnya. ${ }^{15}$ Olahraga dibagi menjadi dua kelompok, yaitu: olahraga aerobik dan anaerobik. Jenis olahraga aerobik menggunakan energi yang berasal dari pembakaran oksigen dan membutuhkan oksigen. Contoh olahraga aerobik misalnya jogging, treadmill, bersepeda, dan renang. Jenis olahraga anaerobik adalah olahraga yang menggunakan energi dari pembakaran tanpa oksigen, dalam hal ini aktivitas yang terjadi akan menimbulkan hutang oksigen. Contoh olahraga anaerobik ialah lari sprint jarak pendek, bersepeda cepat, dan angkat beban. ${ }^{16}$

Latihan beban adalah latihan yang dilakukan secara sistematis dengan menggunakan beban sebagai alat untuk menambahkan kekuatan otot guna memperbaiki kondisi fisik atlet, mencegah terjadinya cedera, atau untuk tujuan kesehatan. ${ }^{17}$ Pada latihan statis (isometrik) seperti handgrip atau mengangkat beban $20 \mathrm{~kg}$ selama 2-3 menit dapat meningkatkan tekanan diastolik sampai $30 \mathrm{mmHg}$; hal ini akan meningkatkan kerja jantung. ${ }^{18}$

Penelitian ini bertujuan untuk mendapatkan perbandingan tekanan darah sebelum dan sesudah olahraga angkat berat yang dilakukan terhadap pelaku olahraga angkat berat di salah satu tempat gym di kota Manado.

\section{METODE PENELITIAN}

Penelitian ini menggunakan nonrandom sampling dengan desain potong lintang. Tekanan darah sistolik (TDS) dan tekanan darah diastolik (TDD) subjek diukur sebelum dan sesudah olahraga angkat berat dengan menggunakan tensimeter Aneroid. Penelitian dilaksanakan di Hardcore gym Sario pada bulan NovemberDesember 2015. Populasi penelitian ini ialah pelaku olahraga angkat berat di Hardcore Gym Sario berjumlah 38 orang. Teknik pengambilan sampel dalam penelitian ini menggunakan rancangan sampel 
non-probabilitas yaitu teknik pengambilan sampel purposif dengan menjadikan seluruh populasi menjadi sampel penelitian. Subjek yang bersedia, menandatangani lembar persetujuan (informed consent).

Dalam penelitian ini, perlakuan yang diberikan dengan mengukur tekanan darah sebelum dan sesudah olahraga. Pengukuran tekanan darah dilakukan dengan menggunakan alat tensimeter aneroid sebelum dan sesudah olahraga. Sebelum olahraga, untuk pengukuran subjek diminta duduk dulu selama kurang lebih 3 sampai 5 menit. Setelah olahraga, pengukuran lansung dilakukan. Pada tiap pengukuran dilakukan sebanyak 3 kali guna menghindari kesalahan penghitungan peneliti agar hasil pengukuran dapat dipertanggung jawabkan.

Analisis data dilakukan dengan pengolahan menggunakan SPSS 21. Data diuji normalitasnya dengan uji Shapiro-Wilk, selanjutnya di uji dengan uji t berpasangan jika data terdistribusi normal, tetapi bila data tidak terdistribusi normal digunakan uji Wilcoxon signed rank test.

\section{HASIL PENELITIAN}

Penelitian ini dilaksanakan pada bulan November sampai bulan Desember 2015 di Hardcore Gym Sario Manado. Subjek penelitian ialah pelaku gym sebanyak 38 orang. Tabel 1 menunjukkan bahwa kelompok terbesar subyek terdapat pada usia 2030 tahun yakni sebanyak 24 orang $(63,2 \%)$ dibandingkan dengan usia 31-40 sebanyak 10 orang $(26,3 \%)$ dan usia 41-50 tahun sebanyak 4 orang $(10,5 \%)$.

Tabel 1. Distribusi karakteristik subyek berdasarkan usia

\begin{tabular}{ccc}
\hline Usia (tahun) & $\mathbf{N}$ & $\mathbf{\%}$ \\
\hline $20-30$ & 24 & 63,2 \\
$31-40$ & 10 & 26,3 \\
$41-50$ & 4 & 10,5 \\
Jumlah & 38 & 100,0 \\
\hline
\end{tabular}

Tabel 2 memperlihatkan distribusi karakteristik subyek berdasarkan jenis kelamin. Jumlah terbanyak berjenis kelamin laki-laki yakni sebanyak 27 orang $(71,1 \%)$ sedangkan yang berjenis kelamin perem- puan sebanyak 11 orang $(28,9 \%)$.

Tabel 2. Distribusi karakteristik subyek berdasarkan jenis kelamin

\begin{tabular}{ccc}
\hline Jenis Kelamin & n & \% \\
\hline Laki-laki & 27 & 71,1 \\
Perempuan & 11 & 28,9 \\
Jumlah & 38 & 100,0 \\
\hline
\end{tabular}

Tabel 3 menampilkan hasil nilai rerata tekanan darah sistolik (TDS) sebelum

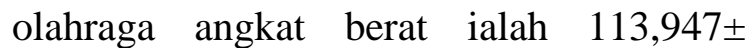
$7,8290 \mathrm{mmHg}$ dengan nilai minimum dan maksimum 100,0 mmHg dan 130,0 mmHg. Nilai rerata TDS sesudah olahraga angkat berat ialah 197,315 $\pm 9,4871 \mathrm{mmHg}$ dengan nilai minimum dan maksimum 178,0 $\mathrm{mmHg}$ dan 220,0 $\mathrm{mmHg}$.

Tabel 3. Hasil statistik tekanan darah sistolik sebelum dan sesudah olahraga angkat berat

\begin{tabular}{ccc}
\hline $\begin{array}{c}\text { TDS } \\
(\mathbf{m m ~ H g})\end{array}$ & Sebelum & Sesudah \\
\hline Rerata & 113,947 & 197,315 \\
Standar & 7,8290 & 9,4871 \\
$\begin{array}{c}\text { Deviasi } \\
\text { Nilai }\end{array}$ & 100,0 & 178,0 \\
$\begin{array}{c}\text { Minimum } \\
\text { Nilai }\end{array}$ & 130,0 & 220,0 \\
Maksimum & & \\
\hline
\end{tabular}

Tabel 4 menyajikan nilai rerata-rata tekanan darah diastolik (TDD) sebelum olahraga angkat berat ialah $77,157 \pm 5,3551$ $\mathrm{mmHg}$ dengan nilai minimum dan maksimum $60,0 \mathrm{mmHg}$ dan $84,0 \mathrm{mmHg}$. Nilai rerata TDD sesudah olahraga angkat berat ialah $95,473 \pm 4,0983 \mathrm{mmHg}$ dengan nilai minimum dan maksimum $90,0 \mathrm{mmHg}$ dan $100,00 \mathrm{mmHg}$.

Tabel 4. Hasil statistik tekanan darah diastolik sebelum dan sesudah olahraga angkat berat

\begin{tabular}{ccc}
\hline $\begin{array}{c}\text { TDD } \\
(\mathbf{m m ~ H g})\end{array}$ & Sebelum & Sesudah \\
\hline Rerata & 77,157 & 95,473 \\
Standar & 5,3551 & 4,0983 \\
Deviasi & & \\
Minimum & 60,0 & 90,0 \\
Maksimum & 84,0 & 100,0 \\
\hline
\end{tabular}


Hasil penelitian memperlihatkan nilai rerata TDS dan TDD subyek penelitian mengalami peningkatan yang bermakna yaitu $83,368 \mathrm{mmHg}$ dan $18,316 \mathrm{mmHg}$ sesudah berolahraga. Uji normalitas data menggunakan uji Shapiro-Wilk memperlihatkan tidak semua data terdistribusi normal. Data yang terdistribusi normal hanya terdapat pada TDS sesudah latihan $(P=0,474>0,05)$ sedangkan untuk TDS sebelum latihan, TDD sebelum dan sesudah latihan didapatkan $P=0,001$ sehingga tidak memenuhi syarat untuk menggunakan uji $\mathrm{T}$ berpasangan (dependent T-test). Uji lanjut menggunakan Wilcoxon signed rank test dengan interval kepercayaan $95 \%$ terhadap
TDS dan TDD sebelum dan sesudah olahraga angkat berat.

Tabel 5 menampilkan terjadi perubahan bermakna $(P<0,05)$ terhadap TDS dan TDD sebelum dan sesudah olahraga angkat berat berupa peningkatan tekanan darah baik TDS maupun TDD. Pada TDS didapatkan selisih rerata sebesar 83,368 mmHg dan pada TDD didapatkan selisih rerata $18,316 \mathrm{mmHg}$. Gambar 1 menunjukkan terjadinya peningkatan TDS dan TDD sebelum dan sesudah olahraga angkat berat dengan nilai rata-rata masing-masing sebesar $113,947 \mathrm{mmHg}$ dan $77,157 \mathrm{mmHg}$ menjadi $197,315 \mathrm{mmHg}$ dan $95,473 \mathrm{mmHg}$.

Tabel 5. Analisa uji Wilcoxon signed rank test

\begin{tabular}{lccccc}
\hline Parameter & \multicolumn{5}{c}{ Rerata } \\
\hline & Sebelum & Sesudah & Selisih rerata & $\mathrm{Z}$ & $\mathrm{P}$ \\
TDS & 113,947 & 197,315 & 83,368 & 5,377 &, 000 \\
TDD & 77,157 & 95,473 & 18,316 & 5,400 &, 000 \\
\hline
\end{tabular}

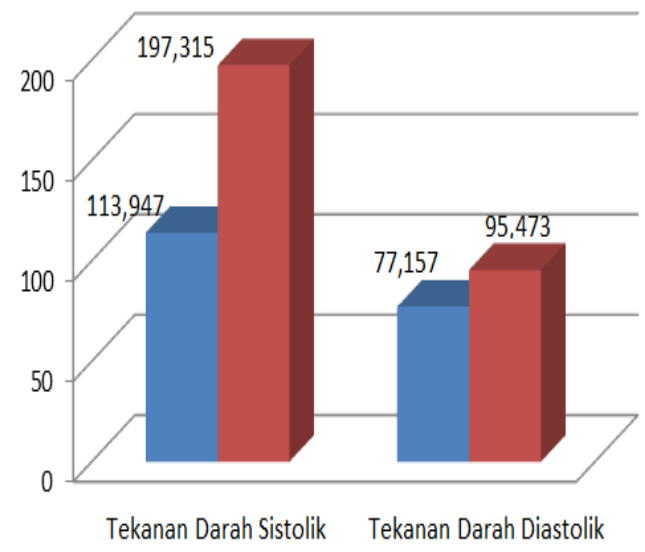

Gambar 1. Peningkatan TDS dan TDD sebelum dan sesudah olahraga angkat berat

\section{BAHASAN}

Angkat berat termasuk dalam rumpun olahraga anaerobik. Olahraga jenis ini tidak menggunakan seluruh otot yang ada pada tubuh, dengan tujuan untuk menguatkan bagian otot tertentu atau untuk meningkatkan massa otot. Selama berolahraga angkat besi tubuh tidak menggunakan oksigen dalam proses pembentukan energi, namun tubuh akan menghasilkan asam laktat, yaitu hasil dari pembakaran glikogen menjadi energi. Berolahraga angkat berat secara intens membuat otot menjadi lelah karena terbentuknya luka kecil di serat-serat otot dan jaringan ikatnya sehingga membutuhkan waktu yang banyak untuk beristirahat dan sumber makanan yang ikut membantu mempercepat proses pemulihan yakni terbentuknya otot-otot baru. ${ }^{19}$

Selama latihan anaerob, permintaan oksigen di otot aktif meningkat, lebih banyak nutrisi digunakan dan proses metabolisme dipercepatkan serta menghasilkan sisa metabolisme. Jadi, untuk memberikan 
lebih banyak nutrisi dan untuk menghilangkan sisa metabolisme, sistem kardiovaskuler harus beradaptasi untuk memenuhi tuntutan sistem muskuloskeletal selama latihan. ${ }^{19}$ Respon akut atau langsung yang terlihat sewaktu latihan ialah peningkatan kontraktilitas miokard, peningkatan curah jantung, peningkatan denyut jantung, tekanan darah dan respon perifer termasuk vasokonstriksi umum pada otot-otot dalam keadaan istirahat, ginjal, hati, limpa dan daerah splanknikus ke otot-otot kerja. Juga didapatkan peningkatan TDS akibat curah jantung yang meningkat. Dengan pelatihan berlanjut maka terjadi penurunan denyut nadi dan pengurangan tekanan darah saat istirahat disertai peningkatan volume darah dan hemoglobin. ${ }^{10}$

Berdasarkan hasil penelitian, pada analisa univariat didapatkan subyek penelitian sebanyak 3 kelompok usia yaitu usia 20-30 tahun, 31-40 tahun, dan 41-50 tahun. Subjek terbanyak berusia 20-30 tahun $(63,2 \%)$, diikuti dengan usia 31-40 (26,3\%), dan usia 41-50 tahun (10,5\%). Berdasarkan jenis kelamin didapatkan bahwa subyek laki-laki $(71,1 \%)$ lebih banyak dibandingkan perempuan $(28,9 \%)$. Hal ini menunjukkan bahwa minat terhadap olahraga angkat berat dipengaruhi oleh usia dan jenis kelamin. Diasumsikan bahwa hal ini disebabkan karena sistem kardiorespirasi atau daya tahan tubuh kardiorespirasi (aerobic capacity) berbeda menurut jenjang usia maupun jenis kelamin. Daya tahan kardiovaskuler menunjukkan suatu tendensi meningkat pada masa anakanak sampai sekitar 20 tahun dan mencapai maksimal di usia 20-30 tahun. Daya tahan tersebut akan menurun sejalan dengan bertambahnya usia, dengan penurunan 8$10 \%$ per dekade untuk individu yang tidak aktif, sedangkan untuk individu yang aktif penurunannya sebesar $4-5 \%$ per dekade. ${ }^{20}$ Kemampuan aerobik maksimal (VO2 max) pada perempuan lebih rendah dibandingkan dengan laki-laki, yaitu sekitar 15-25\%. Perbedaan VO2 max kedua jenis kelamin tidak tampak pada usia muda, paling jelas selama dewasa atau setengah baya. Hal ini berhubungan dengan fakta seperti yang disebutkan sebelumnya bahwa perbedaan ukuran tubuh dan komposisi tubuh antara laki-laki dan perempuan sangat sedikit sebelum pubertas namun perbedaanya sangat besar saat dewasa. ${ }^{21}$

Peningkatan bermakna tekanan sistolik dan nadi disebabkan ejeksi darah oleh ventrikel kiri secara lebih cepat dan kuat, yang menyebabkan suatu peningkatan rerata tekanan darah arterial. Saat melakukan aktivitas aerobik, tekanan darah akan naik cukup banyak. Selama melakukan latihan aerobik yang berat, TDS dapat naik menjadi $150-200 \mathrm{mmHg}$ dari TDS istirahat sebesar 110-120 mmHg. Demikian juga setelah latihan aerobik selesai, tekanan darah akan turun sampai di bawah normal dan berlangsung selama 30-120 menit. $^{22}$

Kenaikan frekuensi denyut jantung dan aktivitas paru akan sesuai dengan intensitas latihan. Semakin tinggi intensitas (misal berjalan, berlari, bersepeda, dan berenang semakin cepat) maka denyut jantung akan terasa semakin cepat yang sesuai dengan azas Conconi, yaitu terdapat hubungan linier antara frekuensi denyut jantung dan intensitas latihan. Selain itu dikenal juga istilah titik defleksi (deflection point) atau ambang batas anaerobik (anaerobic threshold), yang menyatakan bahwa jika intensitas latihan dinaikkan, maka tekanan darah, frekuensi denyut jantun, dan fungsi paru akan meningkat. ${ }^{23}$

Meningkatnya hormon epinefrin saat latihan beban berat akan menyebabkan semakin kuatnya kontraksi otot jantung. Meskipun demikian TDS tidak langsung melonjak tinggi, karena pengaruh epinefrin pada pembuluh darah dapat menyebabkan pelebaran (dilatasi). Pelebaran pembuluh darah sangat tergantung kondisinya. Jika pembuluh sudah mengalami arteriosklerosis, maka pembuluh darah akan kaku dan tidak elastis sehingga pelebaran menjadi terbatas. Dengan demikian kenaikan tekanan darah saat latihan dapat terjadi. Peningkatan pelebaran pembuluh darah saat latihan juga disebabkan karena meningkatnya suhu tubuh. Banyaknya keringat yang keluar akan menyebabkan plasma darah keluar dan volume darah 
menurun, sehingga tekanan darah tidak naik berlebihan. Selisih TDS dan TDD akan meningkat, yang berhubungan erat dengan volume darah sedenyutan yang keluar dari jantung. Tekanan darah baik TDS maupun TDD dapat meningkat sangat tinggi ketika seorang atlet angkat besi mengangkat barbel. Tekanan darah sistolik dapat meningkat dari $120 \mathrm{mmHg}$ sampai $180 \mathrm{mmHg}$. Hal ini terjadi karena banyak otot rangka yang berkontraksi sehingga mendesak pembuluh-pembuluh darah. Tekanan yang naik cukup tinggi tersebut terjadi hanya sesaat, begitu angkatan dilepaskan akan turun kembali ke normal. Agar tidak mengalami hal yang fatal maka penyandang tekanan darah tinggi jika berolahraga harus berhati-hati, jangan melaksanakan dengan intensitas tinggi secara mendadak. Perlu disiapkan lebih dahulu semua otot agar pembuluh-pembuluh darah di seluruh tubuh sudah melebar. Jika pembuluh belum siap, sedangkan jantung memompa dengan kuat sangat dimungkinkan adanya kenaikan tekanan yang cukup tinggi. Oleh karena itu jangan mengangkat beban yang sangat berat secara mendadak. $^{24}$

Berdasarkan hasil analisis, didapatkan TDS terendah sebelum olahraga angkat berat ialah $100 \mathrm{mmHg}$ dan tertinggi 130 mmHg dengan nilai rerata $113,947 \mathrm{mmHg}$, sedangkan TDS terendah sesudah olahraga angkat berat ialah $178 \mathrm{mmHg}$ dan tertinggi $220 \mathrm{mmHg}$ dengan nilai rerata 197,315 $\mathrm{mmHg}$. Perubahan yang terjadi ialah peningkatan TDS sesudah olahraga angkat berat. Pengukuran TDD terendah sebelum olahraga angkat berat ialah $60 \mathrm{mmHg}$ dan tertinggi $84 \mathrm{mmHg}$ dengan nilai rerata $77,157 \mathrm{mmHg}$ sedangkan hasil pengukuran TDD terendah sesudah olahraga angkat berat ialah $90 \mathrm{mmHg}$ dan terendah 100 $\mathrm{mmHg}$ dengan nilai rerata $95,473 \mathrm{mmHg}$. Baik hasil pengukuran TDS maupun TDD menunjukkan perubahan sesudah olahraga angkat berat dikarenakan meningkatnya tekanan darah sesudah olahraga angkat berat. Peningkatan nyata dari TDS dan nadi disebabkan oleh ejeksi darah oleh ventrikel kiri secara lebih cepat dan kuat yang berakibat lanjut suatu peningkatan rerata tekanan darah arterial. ${ }^{22}$ Dapat disimpulkan bahwa terdapat hubungan yang kuat antara berolahraga angkat berat dengan perubahan tekanan darah.

Hasil pengukuran tekanan darah sebelum dan sesudah olahraga angkat berat mengalami perubahan bermakna $(P<0,05)$. Pada penelitian ini besar peningkatan TDS berkisar 20-60 mmHg. Hasil ini sejalan dengan penelitian yang didapatkan saat berolahraga berat yaitu TDS dapat naik menjadi $150-200 \mathrm{mmHg}$ dari TDS ketika beristirahat sebesar $110-120 \mathrm{mmHg}{ }^{24}$

Terdapat perbedaan TDS berupa peningkatan bermakna sebesar 83,368 $\mathrm{mmHg}$ yang merupakan selisih antara TDS sebelum berolahraga angkat berat sebesar 113,947 mmHg dengan TDS sesudah berolahraga angkat berat sebesar 197,315 mmHg. Demikian juga TDD mengalami peningkatan bermakna sebesar 18,316 mmHg yang merupakan selisih antara TDD sebelum berolahraga angkat berat sebesar 77,157 mmHg dengan TDD sesudah berolahraga angkat berat sebesar 95,473 mmHg. Dapat disimpulkan bahwa terdapat perbedaan hasil pengukuran tekanan darah sebelum dan sesudah olahraga angkat berat.

\section{SIMPULAN}

Berdasarkan hasil penelitian dapat disimpulkan bahwa terdapat perbedaan tekanan darah sistolik dan diastolik yang bermakna antara sebelum dan sesudah olahraga angkat berat. Rerata peningkatan dari sebelum olahraga dan sesudah olahraga angkat berat yaitu $83,368 \mathrm{mmHg}$ untuk TDS dan 18,316 mmHg untuk TDD.

\section{SARAN}

Disarankan untuk para pelaku gym agar membiasakan pola hidup sehat seperti tidak rokok, hindari stres, dan makanan pemicu hipertensi.

Pada penelitian lanjut disarankan untuk menggunakan subyek pelaku gym yang non-atletik dengan melibatkan tekanan darah, kapasitas udara dalam paru, indeks masa tubuh (IMT), suhu tubuh, durasi bervariasi, serta pola hidup pelaku gym. 
DAFTAR PUSTAKA

1. Barbeau TR. Cardiovascular Physiology. Florence: Francis Marion University, 2004.

2. Hayens B, Frans HH, Leenen MD, Soetrisno E. Buku Pintar Menaklukkan Hipertensi. Jakarta: Ladang Pustaka, 2003.

3. Guyton AC, Hall JE. Buku Ajar Fisiologi Kedokteran (9th ed). Jakarta: EGC, 1997; p.208-12, 219-23, 277-82, 285-7.

4. Potter PA, Perry AG. Buku Ajar Fundamental Keperawatan Konsep, Proses, dan Praktik Volume 1 (4th ed). Jakarta: EGC, 2005.

5. Oxford Consice Medical Dictionary (6th ed). New York: Oxford University Press, 2003.

6. Smeltzer SC, Bare BG. Buku Ajar Keperawatan Medikal Bedah Brunner \& Suddart Volume 3 (8th ed). Waluyo A, alih bahasa. Jakarta: EGC, 2002.

7. Chobanian AV, Bakris GL, Black HR, Chusman WC, Green LA, Izzo JL, et al. The seventh report of the Joint National Commite on Prevention, Detection, Evaluation, and Treatment of High Blood Pressure: The JNC 7 Report. JAMA. 2003;289;2560-72.

8. Kozier B, Erb G, Berman A, Snyder SJ. Buku Ajar Fundamental keperawatan Konsep, Proses \& Praktek (5th ed). Eny M, Esti W, Devi Y, alih bahasa. Jakarta: EGC, 2009.

9. Miller C. Factors affecting blood pressure and heart rate. 2010. [cited 2018 Sept 25]. Available from: http: //www.livestrong. com/article/196479-factors-affectingblood-pressure-heart-rate/

10. Weber $\mathbf{C}$. What happens to blood pressure as we age? [cited 2018 Sept 28]. 2007. Available from: http://highblood pressure.about.com/od/highbloodpressu re101/f/faging_and_bp.htm.

11. Sheps SG. Mayo Clinic Hipertensi; Mengatasi Tekanan Darah Tinggi. Jakarta: Intisari Mediatama, 2005.

12. Rusdi, Isnawati N. Awas! Anda Bisa Mati Cepat Akibat Hipertensi \& Diabetes. Yogyakarta: Power Books (IHDINA),
2009.

13. Blood Pressure Assosiation. Healthy lifestyle and blood pressure. Juli 2008. [cited 2018 Aug 27]. Available from: http://www.bloodpressureuk.org/

14. Mutohir TC, Maksum A. Sport Development. Jakarta, PT Indeks, 2007.

15. Ramadhani Y. Analisis faktor-faktor yang mempengaruhi minat olahraga dalam perencanaan sport center di Semarang [Skripsi]. Semarang: Universitas Diponegoro, 2008

16. Hermina S, Dwi P, Edwin B. Pengaruh latihan aerobik dan anaerobik terhadap sistem kardiovaskuler dan kecepatan reaksi. Media Medika Indonesia, 2004;39:74-9.

17. Suharjana. Latihan Beban. Yogyakarta: FIK UNY, 2007.

18. Majid A. Fisiologi Kardiovaskular (2nd ed). Medan: Fakultas Kedokteran Universitas Sumatera Utara, 2005.

19. Wilmore HJ, Costill DL, Kenney WL. Physiology of Sport and Exercise (4th ed). Champaign, IL: Human Kinetics, 2008.

20. Pengertian daya tahan kardiorespirasi artikel dan faktor-faktor yang mempengaruhi daya tahan kardiorespirasi. [cited 2018 Oct 16]. Available from: http://www. sarjanaku.com/2013/04/pengertiandaya-tahan-kardiorespirasi.html

21. Olahraga dan wanita. [cited 2018 Oct 16]. Available from: http:// taufikurrahman.blogspot.com/2013/06/ Olahraga-dan-wanita.html.

22. Philip AI, Jeremy WPT. At a Glance Sistem Kardiovaskuler. Jakarta: EGC, 2010.

23. Conconi F, Borsetto C, Casoni I, Ferrari M. Noninvasive determination of the anaerobic threshold in cyclists in medical and scientific aspects of cycling. In: Burke ER, Newsom MM, editors. Medical and Scientific Aspects of Cycling. Champaign (IL): Human Kinetics, 2008; p. 79-91.

24. Sebastianus, Pranatahadi. Fisiologi Latihan. Yogyakarta: FIK UNY, 2011. 